Emma Linklater $(\underline{\text { emma.linklater@eui.eu }})$ - This is a pre-publication draft

\title{
Copyright: E-books distinguished from software, but not exhausted
}

Decision of Landgericht Bielefeld (German Regional Court) of o5 March 2013, Case No: 4 O I9I/II

According to the German Regional Court of Bielefeld, the CJEU's UsedSoft decision is not transferrable to resale of other digital content and contractual provisions restricting use, insofar as they prohibit resale of downloaded eBooks and audiobooks, do not place a disproportionate disadvantage on consumers.

\section{Legal context}

German and EU copyright provisions

Art.4(2) of the Information Society (InfoSoc) Directive provides for the exhaustion of the copyright holder's distribution right and is implemented by $\S_{1}$ (2) of the German Copyright Act (Urheberrechtsgesetz; UrhG). Although the UrhG does not make any distinction between tangibles and intangibles, the InfoSoc Directive's Recital 29 does make such a distinction. It expressly rejects the exhaustion of 'services, and online services in particular'.

On the $3^{\text {rd }}$ of July 2012, the CJEU responded to a preliminary reference in Case CI28/II Usedsoft v Oracle relating to this issue in the context of digitally downloaded software. In this case, the CJEU found the more specific Software Directive to be the applicable legal instrument, overriding the more general InfoSoc Directive.

Art.4(I) of the Software Directive gives rightsholders the exclusive right to authorise reproduction, adaptation and distribution to the public. Art.4(2) provides that upon first sale of a copy of a computer programme in the Community, the distribution right is exhausted. Art.5(I) stipulates that no authorisation by the rightholder is required for reproduction or adaptation of the programme where necessary for use by the lawful acquirer in accordance with its intended purpose. The CJEU held that the distribution right could be exhausted where the copyright holder has authorised a download of software via the Internet, and that a second or subsequent acquirer could become a 'lawful acquirer'. The provision of Art.5(I) enabled that lawful acquirer to make a copy of the file, without infringing the rightholder's reproduction right.

\section{German contract law}

Under $\$ 307(\mathrm{I})$ of the German Civil Code, contract terms must not unreasonably disadvantage consumers contrary to the requirement of good faith. Under $\$ 307(2)(\mathrm{II})$, an unreasonable disadvantage is presumed to exist if the contract limits the essential rights inherent in the nature of the contract to such an extent that attainment of the purpose of the contract is jeopardised.

\section{Facts of the case}

The defendant, an unnamed retailer, operates a website selling media in both physical and intangible (downloadable eBook and Audio book) formats. Art.ro(3) of 
the terms and conditions for sale provided that "the customer acquires the simple, non-transferable right to use the title offered for personal use only". Additionally, the consumer's ability to copy, modify, transfer, make publically available, resell or use the download for commercial purposes was restricted.

The applicant, a German 'umbrella' consumer organisation ('Verbraucherzentrale Bundesverband';'VZBZ') alleged that the contract clauses restricting use unreasonably disadvantaged consumers. The placement of eBooks and Audiobooks on the website and the use of 'physical goods' language employed would lead consumers to download them in good faith that they would have the same usage rights as for print books or CDs. Further, the contract terms went against the exhaustion principle set out in $\mathrm{I}_{\mathrm{z}}(2)$ UrgH. Relying on UsedSoft, it submitted that exhaustion should apply to both tangibles and intangibles alike, the decisive factor being that the contract concerns a marketable, tradable commodity.

\section{Analysis}

The Court dismissed the action as unfounded. Looking first at the consumer contract at issue, the Court found that the primary purpose contract with the defendant was to enable the consumer to 'use' their desired content; the defendant is therefore only contractually responsible for facilitating the download so that the content can be stored on the consumer's local disk to be accessed at their will. Thus, from a contractual perspective, the contract's purpose is not endangered by limiting further sale or use. Turning to the consumer's perspective, the Court reasoned that because consumers know about the piracy problem and digital copies don't degrade with use, they expect that they won't be allowed to pass on their copies and anticipate that all they will get from the contract is the ability to download the content and the right to its personal use. According to the Court the terms are clear and precise, so as not to mislead the consumer into thinking he's getting a right that can be assimilated to a property right in a physical object.

In this case, the defendant's interest in preventing an uncontrollable and potentially infringing secondary market outweighs the consumer interest in establishing such a market. Since digital files can be transmitted instantly, without loss of quality, there is a strong economic risk for the defendant. It can be noted, however, that no forward and delete technologies (as employed by Usedsoft or Redigi) were mentioned in this case. Accordingly, the consumer interest here is in accessing the download and attaining a copy to read or listen to at will: It is not in being able to sell the file. Further, due to the lower price of downloadable e-book and audio books, 'the average consumer' should be satisfied with the having the file for personal use.

Moving to the exhaustion issue, it reiterates that Community exhaustion applies to the distribution right. The downloading of the file, however, creates a local copy and is therefore an act of reproduction. For a downloaded file to be legally resold, a 
further copy must be made; the distribution right must be exhausted, but also the acquirer must have the ability to lawfully reproduce a copy to enable use. Referring to the Usedsoft case, it reiterates that the conclusions therein are specific to the Software Directive because, through Art. 5(I), reproduction without authorisation is possible where necessary for use of by the lawful acquirer. In UsedSoft, the CJEU did not provide for the exhaustion of the reproduction right itself, but it was the combination of exhaustion of the distribution right and Art. 5(I) which enabled resale of the downloaded software. The InfoSoc Directive on the other hand does not provide for such scenarios. Without an equivalent of Art.5(I), even if the distribution right could be exhausted the necessity of producing a reproduction copy to use the downloaded eBook or audio book would be an infringement.

Lastly, the Court finds that prohibiting copying by a third party or resale of the eBook or Audiobook file does not depart from the essential spirit of \$4/a para.I UrgH. The Court finds that the download and duplication in this case instead are intended and do not arise 'incidentally during a technological process'.

\section{Practical Significance}

One practical element - if not from a copyright perspective then from a business one - is the acceptance by the Court that lower price = lesser rights, and that this is acceptable from a consumer perspective. This may be a relief to the publishing industry, but also contains a warning that for restrictions to personal use only to be warranted, there needs to be a consumer benefit in the form of increased accessibility through affordability.

Unfortunately the significance of this decision is also limited by the lack of any reference to forward and delete technologies, which were seemingly not on the Court's horizon. This limits the standing of the Court's finding that the interest in preserving the rightsholders monopoly outweighs the consumer interest in allowing resale, since with such technologies, the rightsholders interests can be preserved without an impact on piracy (i.e. one that one user's copy will be re-circulated). Further questions may be raised on appeal about the 'reasonable consumer' approach adopted: To assume all consumers are aware of the contractual limitations of their downloaded content likely paints a simplified picture, since the growing number business models promoting lending, sharing and cross-platform access have created a hazy grey-zone where 'personal use' is starting to be less clear.

Undoubtedly, the real significance of this decision comes more from its topicality than its substance. It essentially upholds the status quo; however, with the applicants set to appeal and against the backdrop of the Redigi case in the US and the recent patents for 'forward and delete' technologies granted to tech giants Amazon and Apple, the issue of digital exhaustion does not look likely to go away this easily. Although there is little way a regional court at that could have found UsedSoft to apply outside the (limited) context of the Software Directive, a judgement such as this making its way through the European legal system (again 
Emma Linklater $(\underline{\text { emma.linklater@eui.eu }})$ - This is a pre-publication draft

bearing in mind the music-industry equivalent in the US) could signal alarm bells in the minds of policymakers both sides of the Atlantic. Although politicians have seemingly opted to keep schtum on this issue for the moment, they likely won't be able to do so for long. 